\title{
Endocardite vegetativa em leitões causada por Streptococcus suis sorotipo 9
}

\author{
Thais Schwarz Gaggini ${ }^{1}$ \\ Thomas Bierhals ${ }^{2}$ \\ Glauber Machado ${ }^{2}$ \\ Wagner C. G. Bragança ${ }^{3}$ \\ Fernando Pandolfo Bortolozzo ${ }^{4}$
}

\begin{abstract}
RESUMO
A endocardite vegetativa é uma importante alteração do endocárdio do suíno, quase sempre associada a infecções sistêmicas provocadas por bactérias. Foi identificado como agente causador de endocardite vegetativa Streptococcus suis sorotipo 9, em leitões de 7 a 10 e 30 dias de idade. Esse caso mostrou-se de interesse devido à idade dos animais acometidos e o sorotipo identificado. Por ser uma lesão de causa crônica, a endocardite vegetativa em leitões jovens é considerada incomum, não sendo relatada anteriormente na literatura. Além disso, não foi encontrado relato que relacione o sorotipo 9 como causador de endocardite vegetativa em leitões jovens.
\end{abstract}

Palavras-chave: estreptococos, sorotipagem, suínos.

\section{VEGETATIVE ENDOCARDITIS IN PIGLETS CAUSED BY Streptococcus suis SEROTYPE 9}

\begin{abstract}
Vegetative endocarditis is an important endocardium alteration in swine, related with bacterial systemic infection. It was identified Streptococcus suis serotype 9 as the causative agent of the vegetative endocarditis in piglets with 7 to 10 and 30 days of age. This case arouses interest due the age of the affected animals and the identified serotype. Because it is a chronic injury, the vegetative endocarditis is considered unusual in piglets and it is not report previously in the literature. Furthermore, it was not found report that relates serotype 9 causing vegetative endocarditis in young piglets.
\end{abstract}

Key words: serotyping, streptococcus, swine.

\section{ENDOCARDITIS VEGETATIVA EN LECHONES CAUSADAS POR Streptococcus suis SEROTIPO 9}

\section{RESUMEN}

La endocarditis vegetativa es una importante alteración del endocardio del cerdo, siendo casi siempre asociada las infecciones sistémicas provocadas por bacterias. Fue identificado como un agente causante de endocarditis vegetativa por Streptococcus suis serotipo 9 en cerdos de edad de 7 a 10 y 30 días de edad. Ese caso resultó ser de interés debido a la edad de los animales y el serotipo identificado. Al ser una lesión de causa crónica, endocarditis vegetativa

\footnotetext{
${ }^{1}$ Doutoranda em Ciências Veterinárias Universidade Federal de Uberlândia - UFU. Correspondência.

${ }^{2}$ Médico Veterinário - Gerente Técnico DB Genética de Suínos

${ }^{3}$ Gerente A.G. AGRO Suinocultura

${ }^{4}$ Professor Dr. Universidade Federal do Rio Grande do Sul - UFRGS
} 
en los lechones jóvenes es considerada inusual, no siendo relatada previamente en la literatura. Por otra parte, no se encontró relato que relaciona el serotipo 9 como causador de endocarditis vegetativa causado en lechones jóvenes.

Palabras claves: cerdos, estreptococcus, suerotipado.

\section{INTRODUÇÃO}

A endocardite vegetativa é uma importante alteração do endocárdio do suíno, quase sempre associada a infecções sistêmicas provocadas por bactérias. Os agentes causadores mais frequentes são Streptococcus suis (S. suis) (1), Erysipelothrix rhusiopathiae (2) e, mais raramente, outras bactérias, como Escherichia coli, Trueperella pyogenes, Staphylococcus aureus, Actinobacillus equuli, Pasteurella multocida e Actinobacillus pleuropneumoniae $(2,3)$.

Em geral, a patogenia da endocardite vegetativa está relacionada a uma tromboembolia bacteriana, que acarreta inflamação e infarto do miocárdio. O processo inflamatório associado à exsudação de fibrina promove o desenvolvimento da lesão sobre as válvulas, podendo se disseminar até o endocárdio mural adjacente (4). Animais com endocardite vegetativa podem apresentar sinais de insuficiência cardíaca, como hipertermia (5), dispneia, taquicardia e cianose. Laminite, sinais de desconforto, superfície corporal fria, perda de peso e apatia também podem ser observados. Os animais acometidos são encontrados mortos ou gravemente enfermos (3), porém, podem curar-se, apresentando complicações de insuficiência cardíaca congestiva.

S. suis possui 35 diferentes sorotipos descritos (1), dos quais são associados a doenças os sorotipos $1 / 2,1,2,3,4,5,7,8,9$ e $14(1,6)$. O sorotipo 9 é relacionado com à ocorrência de doenças, particularmente em casos de pleurisia ou pneumonia, meningite e artrite (7) e não a ocorrência de endocardite (8).

O presente relato descreve a ocorrência incomum de endocardite vegetativa em leitões jovens causada por S. suis sorotipo 9, com ênfase aos aspectos epidemiológicos, clínicos e patológicos da infecção por $S$. suis em suínos.

\section{RELATO DE CASO}

As amostras foram coletadas no ano de 2015, em uma granja suína de 1300 matrizes, localizada no Estado de Minas Gerais, Brasil. As instalações continham cinco salas de maternidade com capacidade para alojar 270 fêmeas. Em todos os lotes foi realizado o manejo "todos dentro-todos fora" e o vazio sanitário de três dias. As leitoas de reposição do rebanho foram vacinadas contra infecção por Erisipela, Parvovirose e Leptospirose, com o uso de duas doses de vacina, sendo a primeira dose aplicada aos 190 dias de idade e a segunda dose três semanas após a primeira. Fêmeas multíparas foram vacinadas com apenas uma dose, três semanas pré-cobertura.

A granja apresentou, no período anterior ao surto, taxa de mortalidade média de $8 \%$ na maternidade e de $1,5 \%$ na creche. Porém, durante o surto, foi observada mortalidade de $12 \%$ nas duas fases. Os lotes afetados foram avaliados clinicamente e foram realizadas cinco necropsias de leitões, sendo quatro destes oriundos do setor de maternidade, com idade variando entre 7 e 10 dias e, um do setor de creche, com idade de 30 dias. Os principais sinais clínicos observados nos leitões de maternidade e de creche foram cianose nas extremidades, depressão e apatia. Durante a necropsia foram observadas lesões macroscópicas e coletados fragmentos de coração, pulmão e intestino dos animais, além da coleta de sangue cardíaco. Três dos cinco leitões necropsiados apresentaram endocardite vegetativa (Figura 1) e ascite. $\mathrm{O}$ 
animal de creche, além de apresentar endocardite, revelou aderência do saco pericárdico, enquanto o leitão restante não apresentou alteração macroscópica.

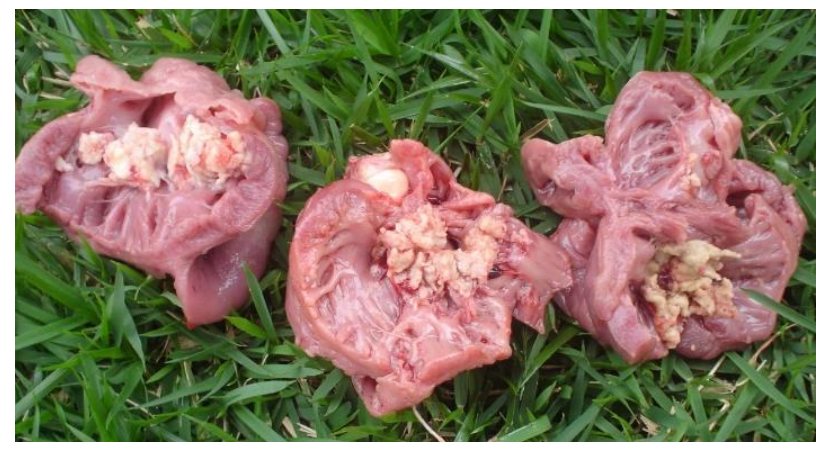

Figura 1. Aspecto macroscópico de lesões de endocardite vegetativa em três leitões com idade entre sete a 10 dias. Minas Gerais, 2016.

O conteúdo purulento da endocardite dos leitões foi encaminhado ao Laboratório de Patologia e Microbiologia da Microvet ${ }^{\circledR}$, Viçosa, para realização do diagnóstico microbiológico. As amostras foram cultivadas em condições de aerobiose em ágar acrescido de sangue ovino $(5 \%)$. Após a incubação à $37^{\circ} \mathrm{C}$ por 24 horas, colônias típicas foram isoladas e submetidas à coloração de Gram e testes bioquímicos para identificação. Os testes bioquímicos acusaram resultado negativo no ágar com $6,5 \%$ de $\mathrm{NaCl}$ no teste VogesProskauer e, reação positiva no teste de amilase (9). As culturas isoladas foram sorotipadas com base no teste de coaglutinação, usando os antisoros hiperimunes de 1 a 9 . Foi utilizado o reagente preparado com Staphylococcus aureus Cowan 1 (10). Para $1 \mathrm{~mL}$ de reagente, $50 \mu \mathrm{L}$ de cada sorotipo hiperimune foi adicionado, homogeneizado e mantido a temperatura controlada por 1 hora, com suaves movimentações da mistura a cada quinze minutos. Após a realização de duas lavagens com solução tampão fostato-salina (PBS), as células ficaram em suspensão em PBS contendo $0,05 \%$ de azida de sódio e $0,1 \%$ de albumina de soro bovino. A massa de células da placa de ágar sangue foi suspensa em $1 \mathrm{~mL}$ de PBS e esterilizada a $121^{\circ} \mathrm{C}$ por 15 minutos. Em uma placa de vidro, uma gota da suspensão foi misturada a uma gota do reagente de coaglutinação, com cada sorotipo. Foi observada por 60 segundos a aglutinação da mistura. Foi utilizado como controle negativo estirpe de Escherichia coli.

No exame anatomopatológico de três amostras de coração foi observada presença de pericardite crônica no leitão de 30 dias e endocardite vegetativa nas outras duas amostras oriundas dos leitões de maternidade. No exame bacteriológico foi isolado S. suis em dois fragmentos de pulmão, em duas amostras de sangue cardíaco e uma amostra de pericardite. Em todos os isolados foi identificado o sorotipo 9 de $S$. suis. Microscopicamente foi observada a presença de infiltrados inflamatórios crônicos e fibrose.

\section{DISCUSSÃO}

Os achados clínicos encontrados nas leitegadas e nos leitões necropsiados foram compatíveis macroscopicamente com endocardite vegetativa (11). A principal suspeita clínica foi infecção por $S$. suis e, baseado nos exames microbiológicos, foi possível confirmar o agente etiológico como $S$. suis sorotipo 9.

S. suis infecta suínos entre 5 e 10 semanas de idade. No entanto, animais jovens também podem ser acometidos, manifestando principalmente quadro de meningite (6). A maioria dos isolados de casos clínicos por $S$. suis pertence aos sorotipos 1/2, 1, 2, 7, 9 e 14 (6). O sorotipo 2 é o predominante na maioria dos países $(6,8)$, apesar de certa variação na localização geográfica (6). Este sorotipo é o principal agente relacionado à ocorrência de meningite em 
suínos, mas também pode causar broncopneumonia, artrite, abscessos, endocardite, poliserosite (12), endometrite, abortamentos (4) e pericardite (13).

O sorotipo 9 é reconhecido como o mais frequentemente isolado na Bélgica, Alemanha e Holanda (6). Em outros países a sua ocorrência é baixa, como no Canadá (2,2\%) (13) e no Brasil (6,4\%) (8), apesar da descrição em casos de surto na América do Norte (14). Dados existentes na literatura indicam que o sorotipo 9 não apresenta grande impacto na produção de suínos e, até o momento, não foi referido como agente causal de endocardite vegetativa em plantéis de suínos no Brasil (14-17). Nesse contexto, o presente estudo descreve pela primeira vez no Brasil a endocardite vegetativa em leitões jovens causada por $S$. suis sorotipo 9. Com efeito, infere-se a importância de se considerar S. suis sorotipo 9 como potencial agente causal de mortalidade de leitões em fase de maternidade e creche, associado a lesões de endocárdio e válvulas cardíacas.

\section{REFERÊNCIAS}

1. Boye M, Feenstra AA, Tegtmeier C, Andresen LO, Rasmussen SR, Bille-Hansen V. Detection of Streptococcus suis by in situ hybridization, indirect immunofluorescence, and peroxidase-antiperoxidase assays in formalin-fixed, paraffin-embedded tissue sections from pigs. J Vet Diagn Invest. 2000;12:224-32.

2. Jensen HE, Gyllensten J, Hofman C, Leifsson PS, Agerholm JS, Boye M, et al. Histologic and bacteriologic findings in valvular endocarditis of slaughter-age pigs. J Vet Diagn Invest. 2010;22:921-7.

3. Katsumi M, Kataoka Y, Takahashi T, Kikiuchi N, Hiramune T. Histologic and bacteriologic findings in valvular endocarditis of slaughter-age pigs. J Vet Med Sci. 1997;59(1):75-78.

4. Sobestiansky J, Barcellos DESN. Doenças dos suínos. 2a ed. Goiânia: Cânone Editorial; 2012.

5. Dewar HA, Jones MR, Griffin SG, Oxley A, Marriner J. A study of experimental endocarditis in pigs. J Comp Pathol. 1987;97(5):567-74.

6. Wisselink HJ, Smith HE, Stockhofe-Zurwieden N, Peperkamp K, Vecht U. Distribution of capsular types and production of muramidase-released protein (MRP) and extracellular factor (EF) of Streptococcus suis strains isolated from diseased pigs in seven European countries. Vet Microbiol. 2000;74(3):237-48.

7. Berthelot-Herault F, Morvan H, Kéribin A-M, Gorrschalk M, Kobisch M. Production of Muraminidase-Released Protein (MRP), Extracellular Factor (EF) and Suilysin by field isolates of Streptococcus suis capsular types 2, 1/2, 9, 7 and 3 isolated from swine in France. Vet Res. 2000;31(5):473-9.

8. Costa ATR, Lobato FCF, Abreu VLV, Assis RA, Reis R, Uzal FA. Serotyping and evaluation of the virulence in mice of Streptococcus suis strains isolated from diseased pigs. Rev Inst Med Trop Sao Paulo. 2005;47(2):113-5. 
9. Gottschalk M, Higgins R, Jacques M, Beaudin M, Henrichsen J. Characterization of six new capsular types (23 through 28) of Streptococcus suis. J Clin Microbiol. 1991;29(11):2590-4.

10. Gottschalk M, Higgins R, Boudreau M. Use of polyvalent coagglutination reagents for serotyping of Streptococcus suis. J Clin Microbiol. 1993;31(8):2192-4.

11. Santos JL, Del'arco AE, Guimarães WV. Aspectos atuais sobre infecção por Streptococcus suis em suínos. In: Anais do 10o Congresso da Associação Brasileira de Veterinários Especialistas em Suínos; 2001; Porto Alegre. Porto Alegre: Universidade Federal do Rio Grande do Sul; 2001.

12. Madsen LW, Svensmark B, Elvestad K, Aalbaek B, Jensen HE. Streptococcus suis serotype 2 infection in pigs: new diagnostic and pathogenetic aspects. J Comp Pathol. 2002;126(1):57-65.

13. Coelho CF, Zlotowski P, Andrade CP, Borowski SM, Gaggini TS, Almeida LL, et al. Pericardite em suínos ao abate no Rio Grande Sul: avaliação de agentes bacterianos e lesões associadas. Pesqui Vet Bras. 2014;34(7):643-8.

14. Gottschalk M, Lacouture S, Bonifait L, Roy D, Fittipaldi N, Grenier D. Characterization of Streptococcus suis isolates recovered between 2008 and 2012 from diseased pigs in Québec, Canada. Vet Microbiol. 2013;162(2-4):819-25.

15. Pagnani KJR, Castro AFP, Gottschalk M, Silveira WD, Nakazato G. Sorotipagem de amostras de Streptococcus suis isoladas de suínos em granjas dos Estados de São Paulo, Minas Gerais e Paraná. Pesqui Vet Bras. 2002;22(1):1-5.

16. Santos JL, Santos LF, Santos DL, Pasqualon HP, Guimarães WV. Agents isolated in pericarditis cases from pigs in the nursery, growing and finishing in Brazil. In: Proceedings of 21st International Pig Veterinary Society Congress; 2010; Vancouver. Vancouver: IPVS; 2010. p.604.

17. Soares TCS, Paes AC. Encefalite dos leitões. In: Megid J, Ribeiro MG, Paes AC. Doenças infecciosas dos animais de produção e de companhia. Rio de Janeiro: Roca; 2016. p.112-9.

Recebido em: Aceito em: 